\title{
ESTUDO DE CASO: ANÁLISE DOS PARÂMETROS DE SEGURANÇA DA BARRAGEM DO BEZERRO NO MUNICÍPIO DE JOSÉ DE FREITAS/PI
}

\author{
CARVALHO, JOÃO \\ Acadêmico de Engenharia Civil \\ Centro Universitário UNINOVAFAPI \\ Piauí; Brasil \\ joaomarcos.souza@hotmail.com
}

\author{
PEDREIRA, ANA \\ Acadêmica de Engenharia Ambiental e Sanitária \\ Centro Universitário UNINOVAFAPI \\ Piauí; Brasil \\ analemospedreira@gmail.com
}

\author{
SANTANA, CLAUDENY \\ Mestre em Engenharia de Transportes \\ Centro Universitário UNINOVAFAPI \\ Piauí; Brasil \\ cldeny@yahoo.com.br
}

\author{
SOUSA, PAULO \\ Acadêmico de Engenharia Ambiental e Sanitária \\ Centro Universitário UNINOVAFAPI \\ Piauí; Brasil \\ paulindomonza@yahoo.com.br
}

\section{RESUMO}

De 2015 para os dias atuais, dois grandes desastres envolvendo barragens marcaram a história do Brasil; Brumadinho/MG (2019) e Mariana/MG (2015) fizeram com que as vistorias de segurança nesse tipo de construção recebessem um olhar mais atencioso. Com menor divulgação, mas ainda de grandioso impacto, o rompimento da Barragem de Algodões (2008), 10 anos depois ainda deixa sequelas no estado do Piauí. Nesse contexto, o presente trabalho tem por objetivo um estudo de caso que analisa os parâmetros de segurança da Barragem do Bezerro no município de José de Freitas/PI, que nos ano de 2018, provocou preocupação na população do entorno ao apresentar fissuras na sua estrutura. A metodologia do trabalho foi baseada na inspeção in loco, verificando quais os tipos de dispositivos de segurança que a barragem possui, avaliando as condições de uso dos mesmos; verificou-se a topografia e relevo do terreno, utilizando dados de sensoriamento remoto através de imageamento por radar do satélite ALOS Palsar; e, por fim, analisou-se, também, a susceptibilidade e erodibilidade do solo do entorno. Os resultados mostraram que a barragem possui apenas dispositivos de medição de pluviosidade e nível, ficando bem aquém do mínimo requerido, além do sangradouro apresentar diversas patologias emergenciais. O estudo é concluído mostrando a necessidade de implementar novos dispositivos de segurança que faltam, além da manutenção dos já existentes, visando à conformidade com o mínimo exigido pela Lei 12.334, Política Nacional de Segurança de Barragens (PNSB).

Palavras-chave: barragem; patologia; dispositivos; segurança.

\section{ABSTRACT}

Since 2015 there is currently a major disaster related to dams that has marked the history of Brazil; Brumadinho/MG (2019) and Mariana/MG (2015) indicate that security inspections in this type of construction receive a more attentive look. With less dissemination, but with a big impact, the rupture of the prey of Algodões (2008), 10 years later, but there are still some in the state of Piaui. In this context, the present work adds a case study analyzing the safety parameters of the prey Calf in the municipality of José de Freitas/PI, which in 2018 has caused concern in the surrounding population to present cracks in its structure. The methodology of the work is based on in situ inspection, checking what types of safety devices are in place, assessing the conditions of use of the same; topography and terrain reliance were verified using remote sensing data via ALOS Palsar satellite radar images; finally, it also analyzed the susceptibility and erosion of its surrounding. The results show that the prey only has flood and level measuring devices, often due to the minimum required, and the prey presents various emergency pathologies. The study concludes by showing the need to implement new missing security devices, in addition to maintaining existing ones, to comply with the minimum required by Law 12.334, National Dam Security Policy (PNSB)

Keywords: dam; pathology; devices; security. 


\section{INTRODUÇ̃̃̃O}

O meio ambiente passou a ser objeto de estudo de pesquisa para planejamento e organização territorial que permite diversas discussões com a sociedade para descobrir métodos que proporcionam melhores condições ambientais que tenham por finalidade promover a qualidade de vida dos habitantes (ROVANI et al., 2015). A ocupação desordenada e acelerada da população resultou no consumo desenfreado dos recursos naturais, tendo como consequência sua exploração de modo mais intenso sem levar em conta suas limitações (SANTOS E SOBREIRA, 2008; PEREIRA et al., 2011; ROVANI et al., 2015).

Para que ocorresse desenvolvimento socioeconômico foi incorporada a construção de barragens ao planejamento de expansão urbana, estrutura que é bastante difundida no Brasil e dependendo de sua finalidade é essencial para assistência social. Essas infraestruturas são parte de um sistema que atende a população e têm diversas aplicabilidades como: Produção de energia elétrica; Abastecimento de água para consumo humano; Abastecimento de água para uso industrial; Irrigação; Regularização de vazões atenuando os efeitos das enchentes e das secas; Navegação; Aquicultura; Recreação; Disposição de rejeitos de mineração; Acumulação de resíduos industriais líquidos (BRASIL, 2015).

A Barragem do Bezerro, mostrada na Figura 2, foi construída no ano de 1993, obra realizada pelo órgão público Instituto de Desenvolvimento Econômico do Piaú - IDEPI, com área total de 720 hectares situada às margens do Riacho Bezerro e da rodovia PI -115. A proposta técnica para a barragem se deu através da construtora Hidros a qual realizou a implantação do empreendimento. Levando em consideração a questão histórica da Barragem do Bezerro, o órgão responsável pelo empreendimento preservou documentos originais que estão relacionados diretamente com a construção da Barragem. Sendo que é de suma importância ressaltar que a conservação de documentos básicos, como, proposta técnica, projeto básicos, estudo do perfil dos solos e outras, são inerentes para uma intervenção posterior mais segura (BRASIL, 2015).

A forma geométrica da barragem é trapezoidal, com coroamento de largura de 5 metros, extensão de $1400 \mathrm{~m}$, e com cota de $102 \mathrm{~m}$. Revestimento de solo laterítico com meio fio, e saída d'água a cada $20 \mathrm{~m}$. O Talude Montante com Inclinação 1:2,5 (V:H) com proteção de Rip-Ra, Jusante com Inclinação 1:2,0 (V:H). A drenagem interna realizada pelo sistema Rock Fill, com cota de $98 \mathrm{~m}$, e folga de $0,68 \mathrm{~m}$. A tomada de água tem o controle a jusante, com comprimento de $20 \mathrm{~m}$, cota de $96 \mathrm{~m}$ diâmetro de $300 \mathrm{~mm}$. O sangradouro é do tipo escavado, foi projetada para altura da lâmina de $0,32 \mathrm{~m}$, largura de $20 \mathrm{~m}$.

A Barragem do Bezerro foi construída em uma área plana em toda sua extensão e vizinhança, como mostrado no mapa a seguir (Figura 3), e, por isso, está mais suscetível ao acúmulo excessivo de água. Fator que também é potencializado pelas chuvas torrenciais que afetam o estado do Piauí (grandes volume em um curto período), além da fragilidade dos dispositivos de segurança e das condições encontradas na parede da barragem.

Dentro deste contexto, obejtiva-se neste trabalho analisar as condições de segurança da Barragem do Bezerro, localizada no município de José de Freitas, Piauí, mediante inspeção in loco e verificação da presença ou ausência e estado de conservação dos dispositivos de segurança.

\section{REFERENCIAL TEÓRICO}

As barragens são reservatórios que por natureza têm certo potencial de risco, o qual não deve ser menosprezado, em vista dos danos econômicos ou até catastróficos, provocados pelos efeitos de operações erradas, o mau funcionamento, ou até ruínas dessas obras. Além do risco que podem ser esperados à existência da barragem com seu reservatório, há eventualmente 14 outros impactos, que dependendo de cada caso, podem provocar modificações e até destruição de ecossistemas e alterações no regime fluvial. Surgências de água com ou sem carreamento de matéria, Erosão superficial, Recalques e abatimentos (sink-holes), Trincas superficiais, Instabilidade de taludes laterais e influência na qualidade da água a jusante (SILVEIRA, 1976).

\subsection{Elementos de uma barragem}

Segundo Carvalho (2008), os principais elementos que são inerentes à construção de uma barragem de terra são: crista; borda livre; talude de montante; proteção do talude de montante (rip-rap); talude de jusante; proteção do talude de jusante (grama ou outro elemento); trincheira de vedação; filtro horizontal; filtro vertical; dreno de pé; cortina de injeção; poço de alívio; tapete impermeável; sistema de drenagem das águas pluviais. 
Além destes elementos, para melhor eficiência do reservatório, também fazem parte da estrutura: Sistema de extravasamento (vertedouro ou sangradouro) e Comportas. A Figura 1, abaixo, representa os elementos básicos de uma barragem de terra convencional (CARVALHO, 2008).

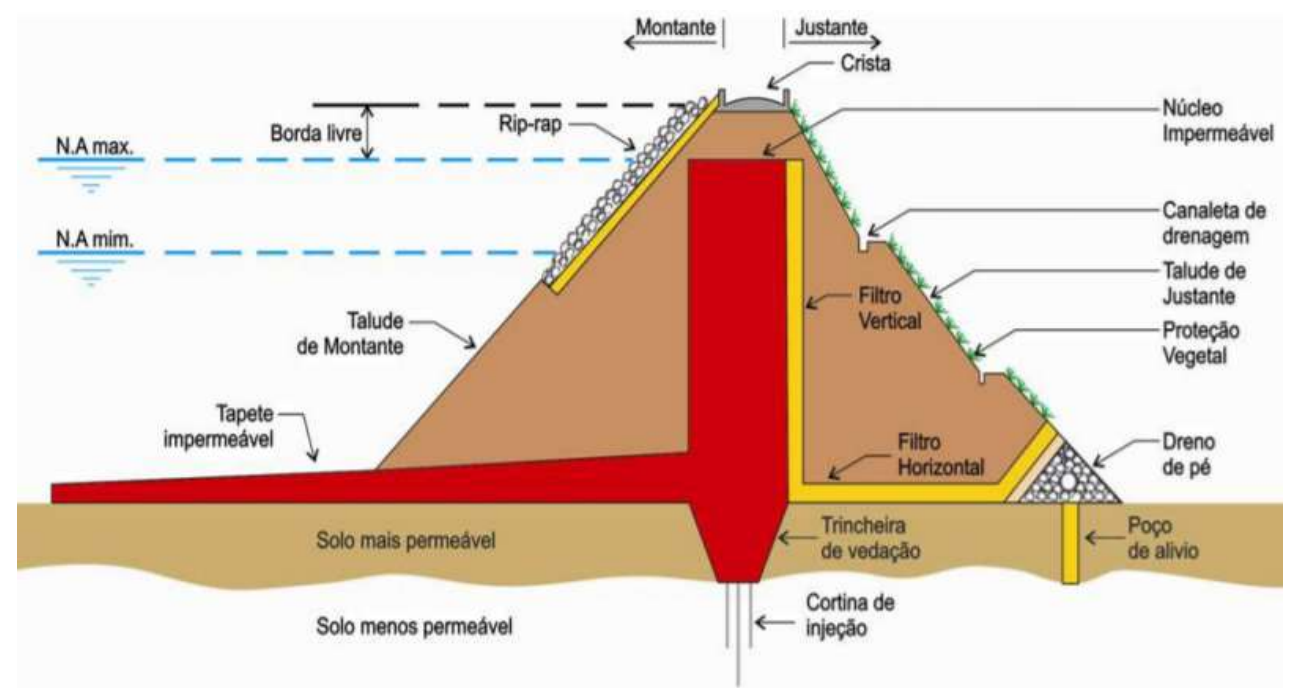

Figura 1: Principais elementos de uma barragem de terra (Fonte: Manual de Segurança de Barragens, 2015)

\subsection{Dispositivos de segurança necessários em uma barragem}

De acordo com o Manual de Segurança e Inspeção de Barragens, os requisitos de manutenção devem ser aplicados a todos os componentes elétricos e mecânicos, essenciais à segurança da barragem, são estes verificados na Tabela 1:

\begin{tabular}{|l|l|}
\hline Dispositivo & Função \\
\hline Acionadores & Alarme para estados de calamidade púbica \\
\hline Bombas & $\begin{array}{l}\text { Normalmente, seu emprego está ligado ao } \\
\text { abastecimento de água advindo do reservatório, ou } \\
\text { no esgotamento de estrutura como casa de força e } \\
\text { galerias. }\end{array}$ \\
\hline Comportas & $\begin{array}{l}\text { Controlar a vazão, podendo com isso também } \\
\text { controlar o nível d'água no reservatório, podem ser } \\
\text { de três tipos: de serviço, de emergência e } \\
\text { manutenção. }\end{array}$ \\
\hline Condutos & Transporte e transmissão de fluidos. \\
\hline Dispositivos de acionamento de comportas & $\begin{array}{l}\text { Atua na detecção de uma cota crítica para abertura } \\
\text { de comportas e, assim, regular a vazão e não } \\
\text { comprometer a parede da barragem. }\end{array}$ \\
\hline Instrumentação & $\begin{array}{l}\text { Conjunto de equipamentos responsáveis pelo } \\
\text { monitoramento contínuo de diversos fatores } \\
\text { relacionados à estabilidade, clima, volume, } \\
\text { pressão, tensão, dentre outros. }\end{array}$ \\
\hline Iluminação normal e de emergência & $\begin{array}{l}\text { Promover a capacidade de trabalho e e } \\
\text { monitoramento durante período noturno ou de } \\
\text { pouca iluminação solar, assim como, durante } \\
\text { ausência de energia elétrica. }\end{array}$ \\
\hline Vertedouro & $\begin{array}{l}\text { Conduzir a água de forma segura através de um } \\
\text { canal, servindo como sistema de escape, } \\
\text { impedindo a passagem da água por cima da } \\
\text { barragem quando ocorrem chuvas ou aumento da } \\
\text { vazão - característica que o torna quesito de } \\
\text { segurança em barragens. }\end{array}$ \\
\hline
\end{tabular}

Tabela 1: Dispositivos de segurança de uma barragem 
Sendo estes citados, os dispositivos necessários para que uma barragem possua o mínimo de segurança requerida pela PNSB (Política Nacional de Segurança de Barragens). O Manual também cita que um programa de manutenção preventiva deve ser planejado de acordo com a classificação por consequência de ruptura da barragem, padrão da indústria, recomendações do fabricante e do histórico operacional de cada peça, em particular do equipamento.

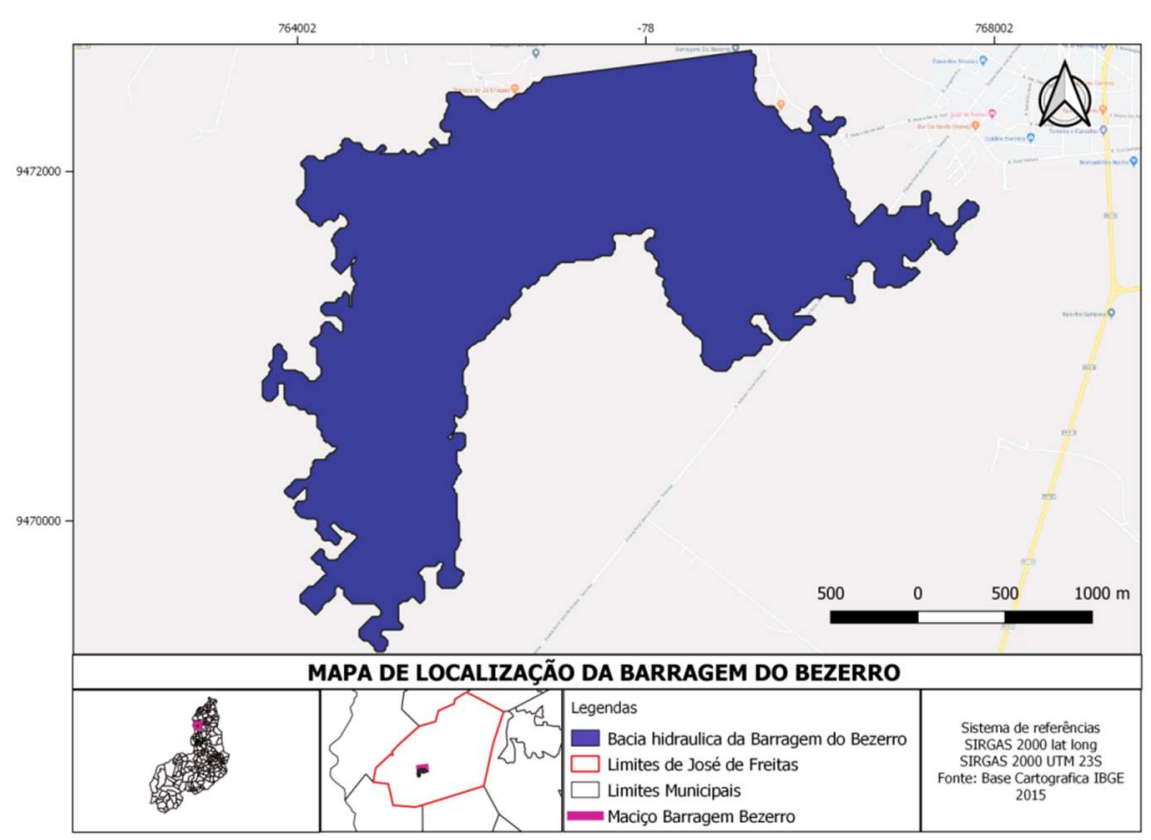

Figura 2: Mapa de localização da Barragem do Bezerro (Fonte: Base Cartográfica IBGE, 2015)

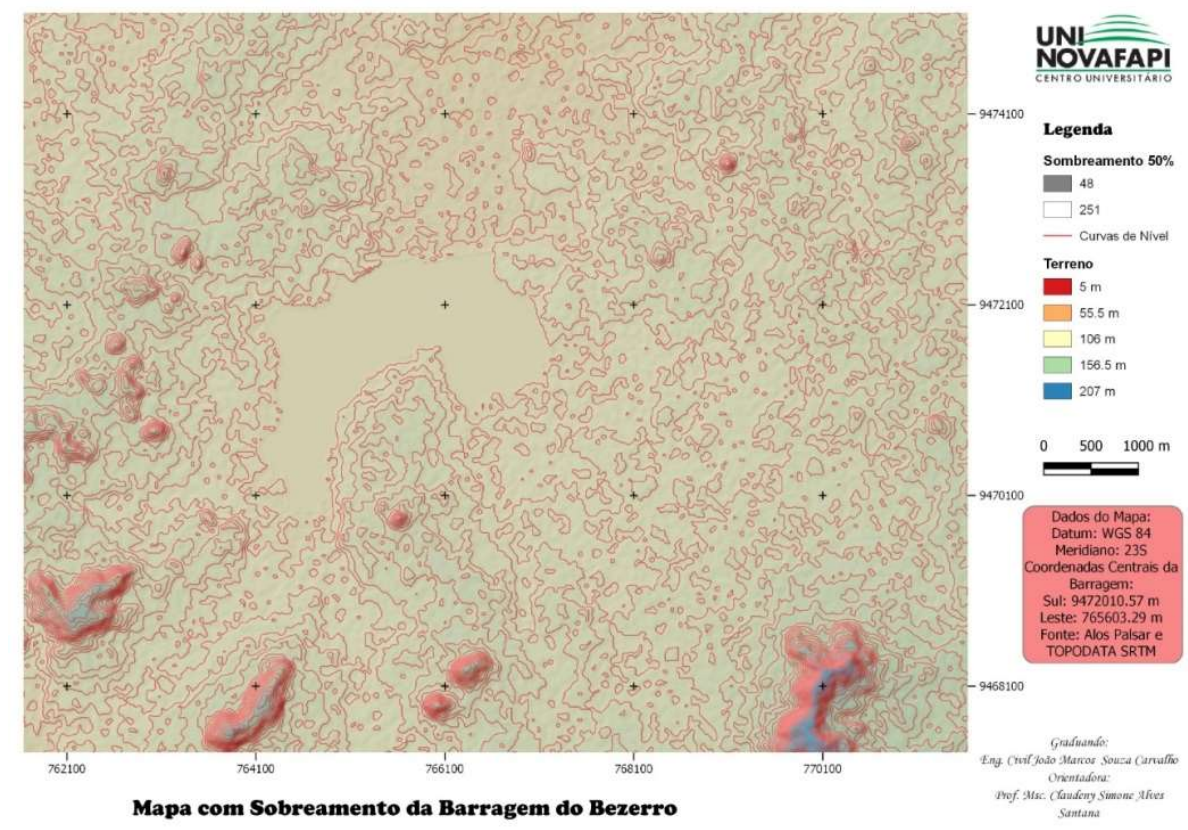

Figura 3: Mapa com sombreamento da Barragem do Bezerro (Fonte: Autor, 2019)

\section{METODOLOGIA}

A metodologia deste estudo consistiu em 04 (quatro) etapas distintas: 
1- Pesquisa de dados de concepção de projetos e informações históricas da Barragem do Bezerro, que podem ser mais bem aprofundados no estudo de Alvarenga e Sousa (2019);

2- Inspeção in loco na Barragem do Bezerro, e aplicação de "check list" adaptado do Manual de Segurança e Inspeção de Barragens (2015) a fim de averiguar a qualidade dos dispositivos de segurança existentes e detectar aqueles que ainda não foram implantados na construção. Além de verificar as condições estruturais da barragem onde foi possível ter acesso. Ainda nesta etapa realizou-se uma catalogação da espessura dos troncos, com auxílio de uma trena, de espécies arbóreas identificadas, que se encontravam nos taludes à montante e à jusante da barragem;

3-Elaboração de mapa de relevo da região com os dados de modelo digital de elevação (MDE) do satélite japonês Alos e o seu sensor de alta frequência por microondas Palsar com objetivo de proporcionar dados de observação da Terra que contribuam ao desenvolvimento sustentável, cartografia topográfica entre outros. Os dados foram tratados no software QGis originando um mapa de relevo com indicação de curvas de nível com equidistância vertical de 5 metros; Também foi utilizado o software Google Earth para elaboração dos croquis de localização dos principais problemas identificados na barragem

4- Consolidação dos dados obtidos para realizar as análises pertinentes ao objetivo desta pesquisa.

\section{RESULTADOS E DISCUSSÕES}

O primeiro dispositivo encontrado foi o acionador ou tomada d'água, logo ao chegar à crista da barragem, do lado direito. A construção que abriga o mesmo está em estado de deterioração, com acúmulo de água parada (Figura 4), restos de vegetação e animais nos canais (Figura 5).

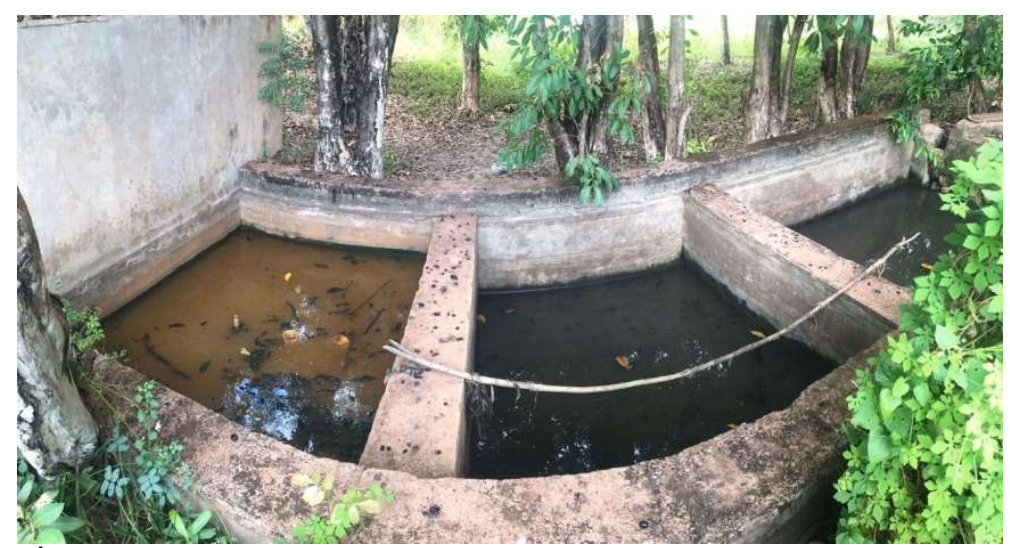

Figura 4: Água parada nos reservatórios do sistema de acionamento (Fonte: Autor, 2019)

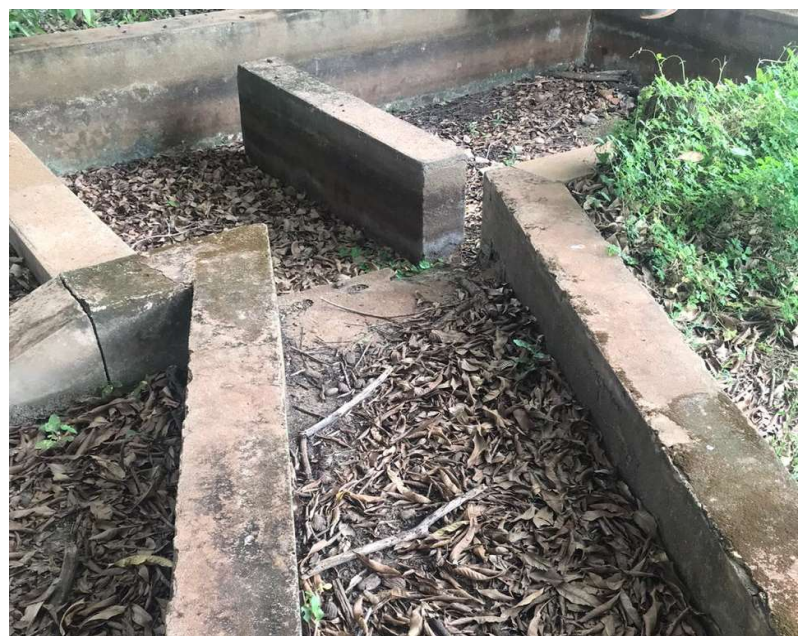

Figura 5: Canais do sistema de acionamento com restos de vegetação e animais (Fonte: Autor, 2019)

O equipamento encontra-se na mesma situação, ou pior (Figuras 6). Não foi constatada data de última vistoria feita, mas verificou-se no próprio equipamento o período de fabricação do mesmo, que datava de 1996. Presume-se, que nenhuma inspeção tenha sido feita, e que nenhuma parte do equipamento nunca tenha sido trocada ou consertada. 


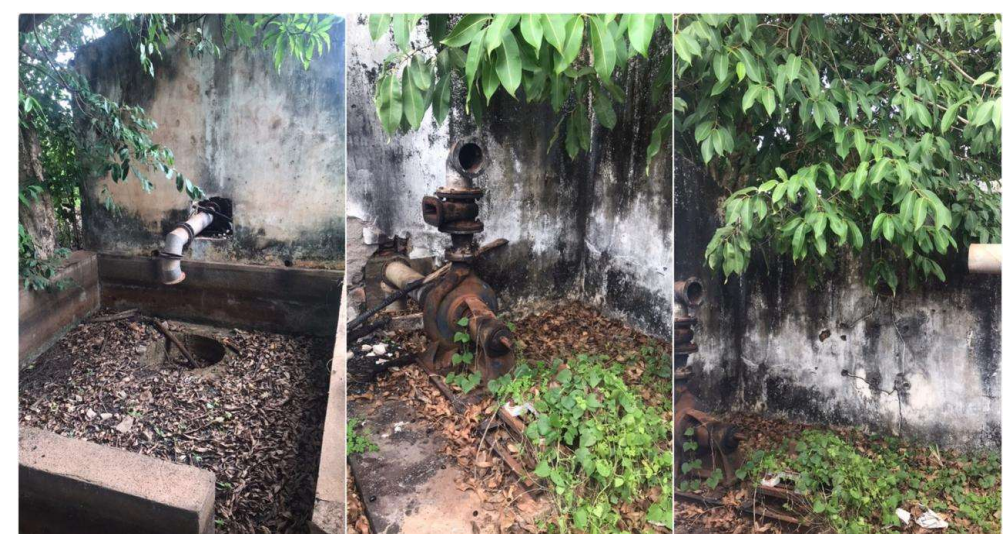

Figura 6: Estado dos condutos e bomba do sistema de acionamento (Fonte: Autor, 2019)

Na mesma distância do início da crista, no lado oposto (à jusante), observou-se que o sistema de gradeamento, onde se inicia o mecanismo de Tomada D’água, encontra-se enferrujado (Figura 7), mas não foi possível constatar se existe obstruções no canal ou não.

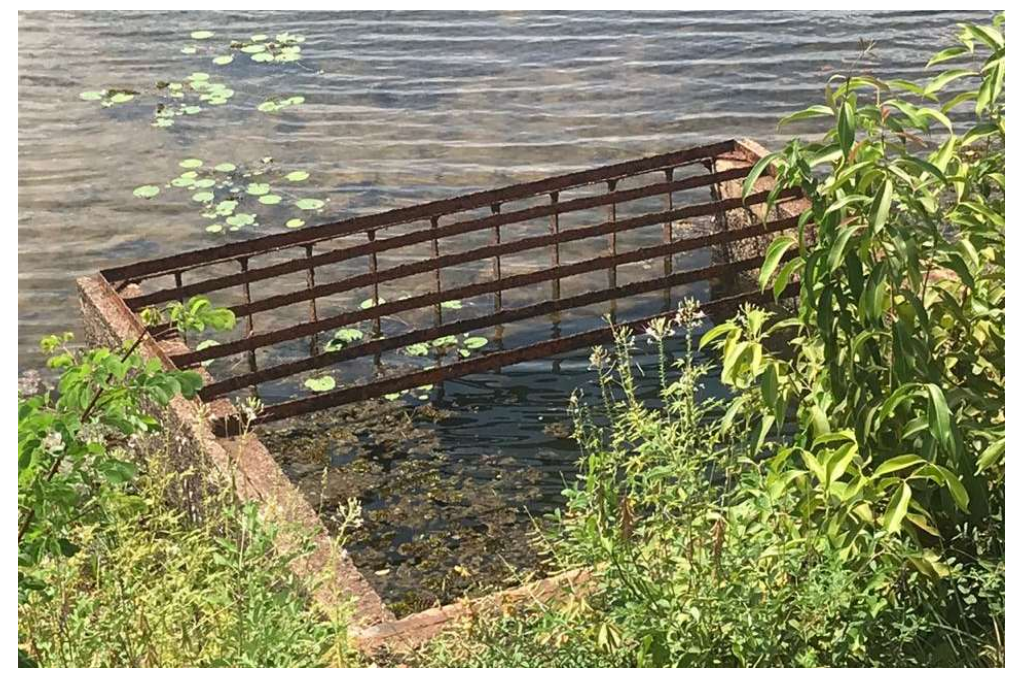

Figura 7: Sistema de gradeamento à jusante da barragem (Fonte: Autor, 2019)

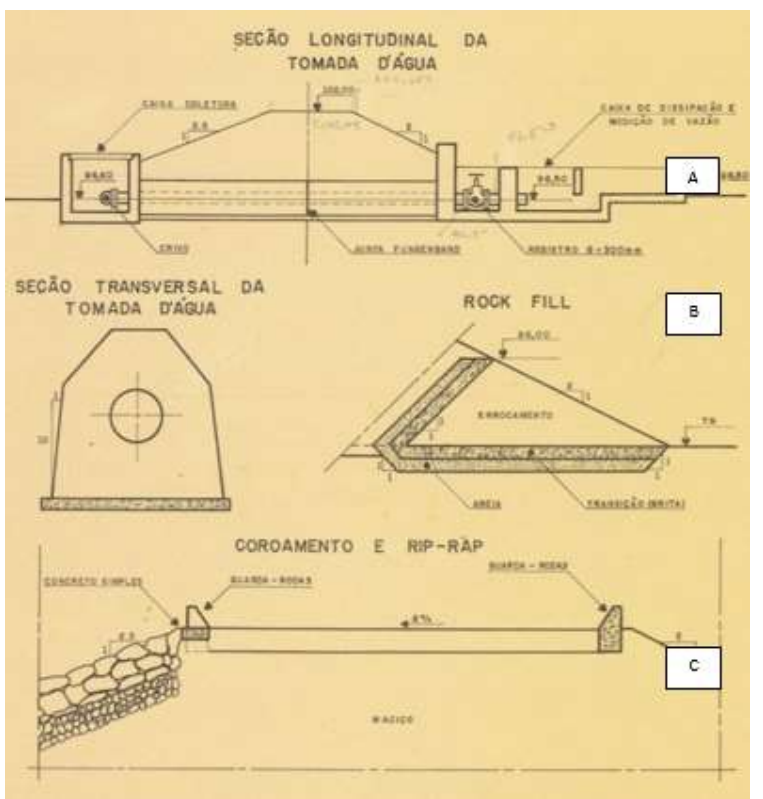

Figura 8: Detalhe da seção longitudinal da Tomada D’água, A, coroamento, B, e do RIP RAP, C (Fonte: IDEPI, 1992) 
Durante o percurso de aproximadamente $1400 \mathrm{~m}$ na crista da barragem constatou-se um número preocupante de espécies arbustivas e arbóreas nos taludes, como verificado nos exemplos das Figuras 9 e 10. Foram catalogadas as larguras dos troncos das espécies que mais se destacavam na paisagem, sendo encontradas 2 espécies preponderantes no talude à montante com troncos de $100 \mathrm{~cm}$ e $130 \mathrm{~cm}$ aproximadamente, próximo ao início e ao final da crista, respectivamente; no talude à montante observou-se a presença de um número bem maior de espécies arbóreas, observou-se 14 espécies mais robustas com troncos que variaram de $13 \mathrm{~cm}$ a $125 \mathrm{~cm}$.

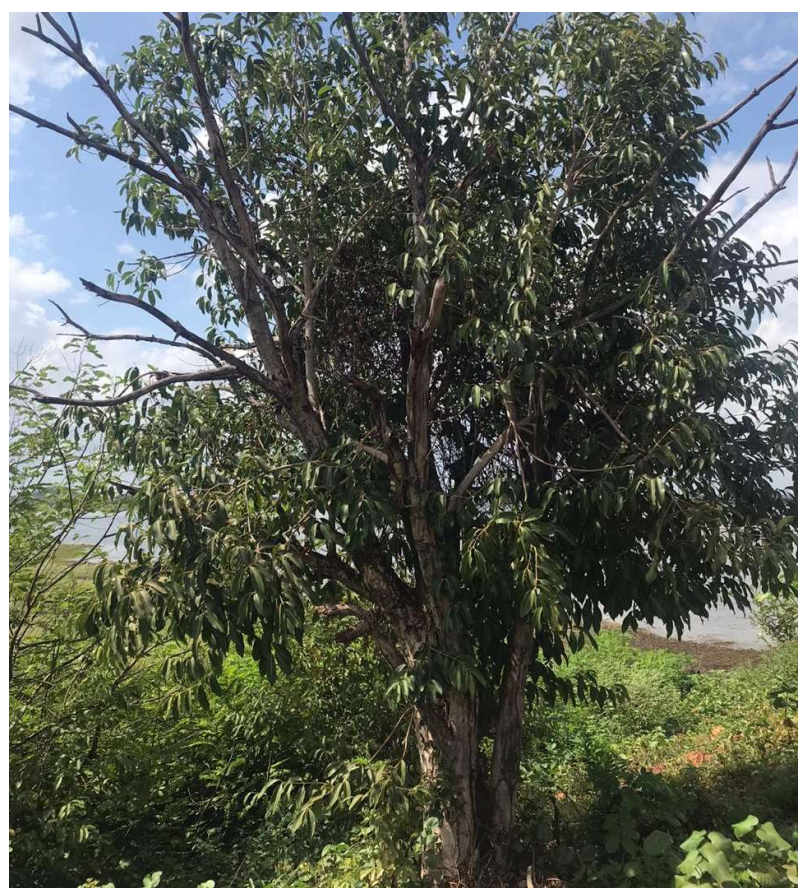

Figura 9: Espécie da família Myrtaceae com tronco de 56cm à jusante da barragem (Fonte: Autor, 2019)

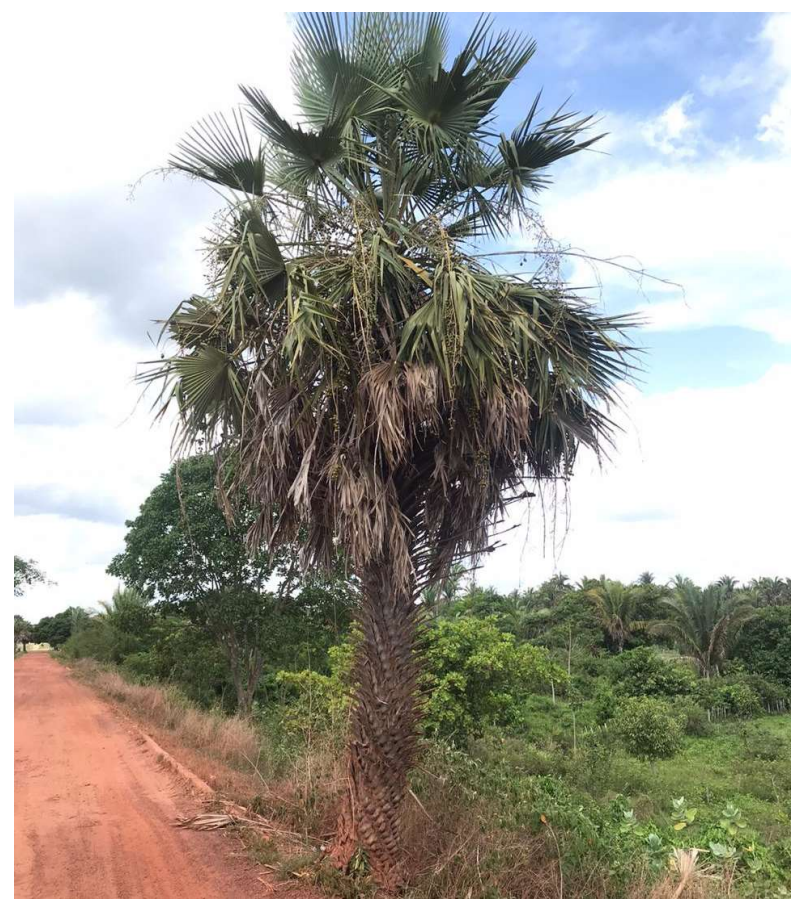

Figura 10: Espécie da família Arecaceae com tronco de $130 \mathrm{~cm}$ à montante da barragem (Fonte: Autor, 2019)

Ainda no talude à jusante da barragem foram observadas várias rochas soltas que deveriam fazer parte do sistema de enroncamento (Figura 11). 


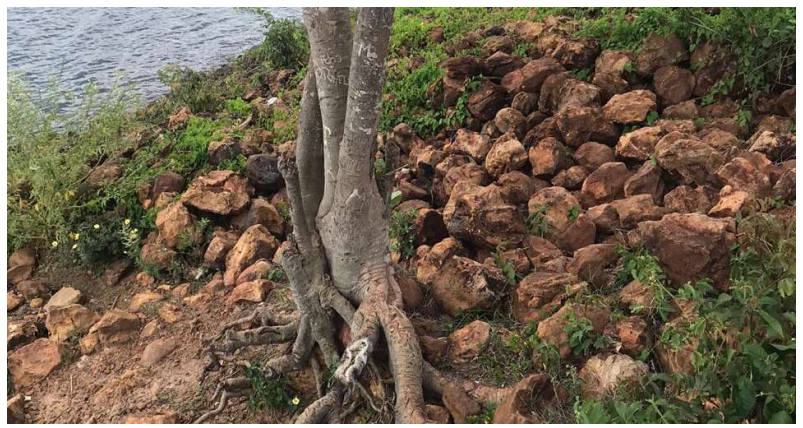

Figura 11: Rochas desprendendo-se do enrocamento devido às raízes das árvores (Fonte: Autor, 2019)

De acordo com matéria do G1 Piauí (novembro, 2018), em abril de 2018 a Barragem do Bezerro sofreu ameaça de rompimento devido ao aumento do volume de água das chuvas que caíram naquela região. Na época, o local recebeu reparos e foi definida uma previsão de início de uma restauração completa e definitiva para o início de janeiro de 2019 , mediada pelo Idepi (Instituto de Desenvolvimento do Piauí).

Durante a vistoria, verificou-se que o local onde a falha estrutural é encontrada está ainda sob reparos provisórios feitos por uma manta de sacos de cimento (Figura 12).

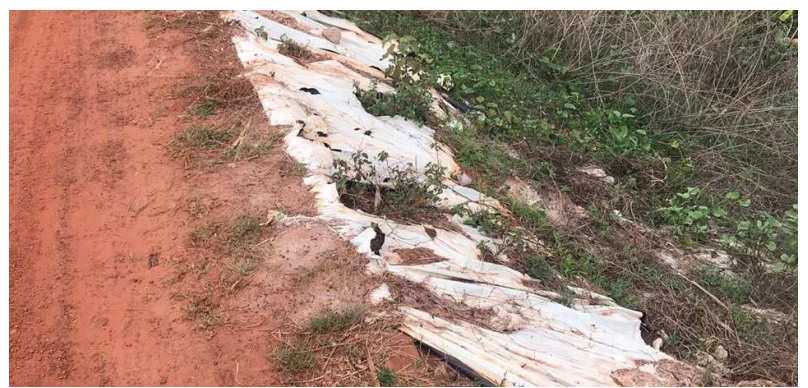

Figura 12: Manta de sacos de cimento feita para reparo provisório de falha estrutural (Fonte: Autor, 2019)

Observou-se também, recalques sucessivos na crista da barragem com um raio de aproximadamente $18 \mathrm{~m}$ do ponto da falha, com profundidades de até $25 \mathrm{~cm}$ nas deformações verticais (Figura 13).

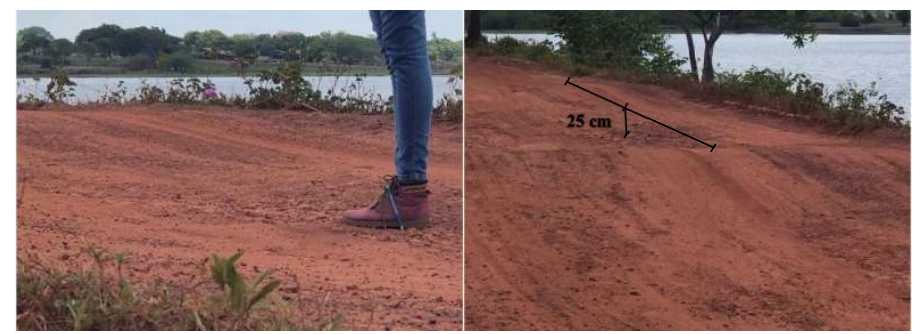

Figura 13: Perspectiva de flecha provocada por recalque na crista da barragem (Fonte: Autor, 2019)

Também nas proximidades do local da avaria, "no pé talude" à montante, constatou-se a presença de muitas plantas pteridófitas da classe das samambaias, e, também, um ponto de infiltração (Figura 14).

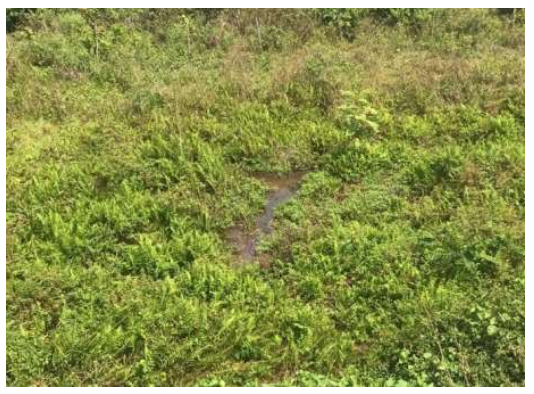

Figura 14: Samambaias e ponto de infiltração próximo ao local da falha estrutural (Fonte: Autor, 2019) 
Durante todo o percurso na crista apurou-se a presença dos dispositivos de drenagem (valetas), que encontram-se quebrados e/ou obstruídos (Figura 15). Estes defeitos condicionam o acúmulo de água na crista barragem, o que propicia umedecimento do solo da crista, favorecendo a infiltração vertical e aumentando a susceptibilidade à deformações.

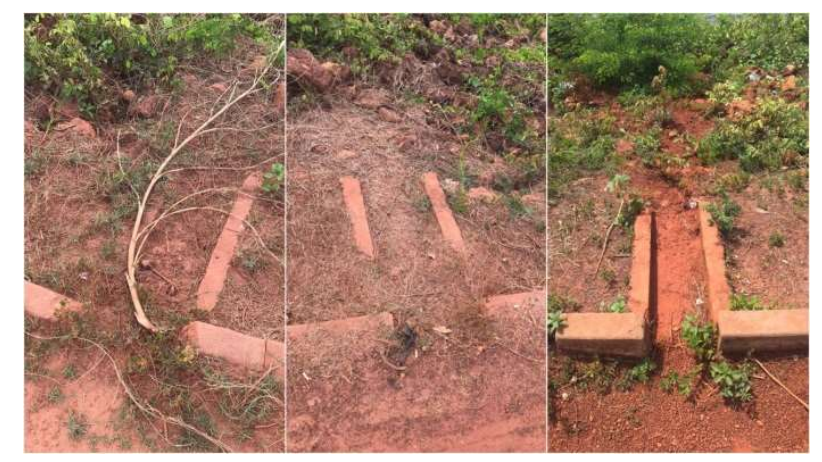

Figura 15: Dispositivos de drenagem da crista da barragem (Fonte: Autor, 2019)

Ao final da crista, foram encontrados níveis de referência (RN) para pontos específícos da barragem. O RN da crista, 102 metros, encontra-se quebrado (Figura 16). Os demais, pé da barragem (101,00 m), nível seco (100,00 m), superfície do espelho $(99,00 \mathrm{~m})$ e interior da água $(98,15 \mathrm{~m})$ estão, respectivamente, retratados na Figura 17, pelos números 1, 2, 3 e 4 .

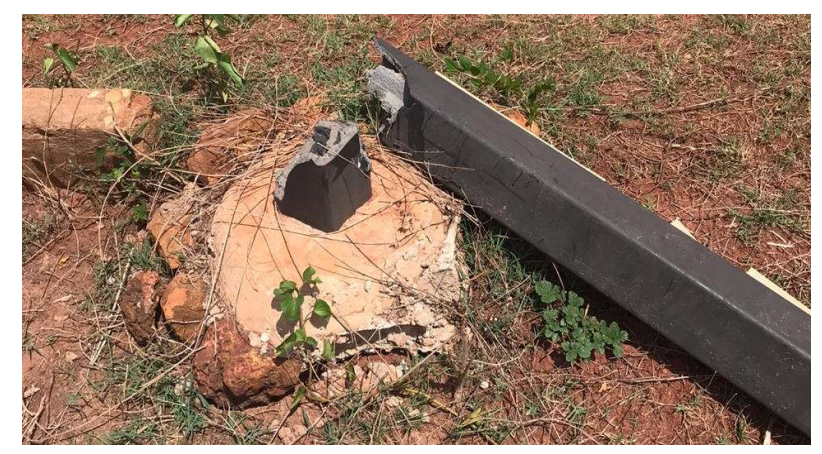

Figura 16: RN da crista (Fonte: Autor, 2019)

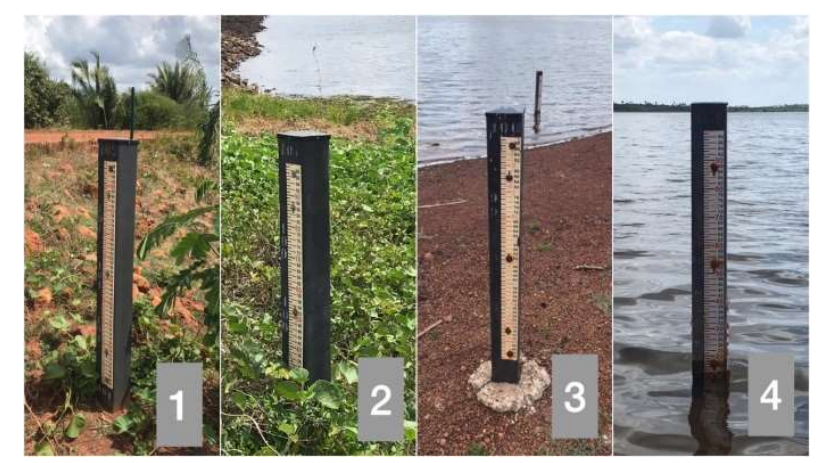

Figura 17: RN de cada ponto específico da barragem (Fonte: Autor, 2019)

A degradação das cotas de nivelamento prejudica a detecção do nível da água quando em períodos de cheia ou estiagem.

O sangradouro encontra-se em situação de degradação do solo, com problemas de erodibilidade do tipo voçoroca devido à ação interna da água que atua nos poros presentes no solo (Figura 18). 


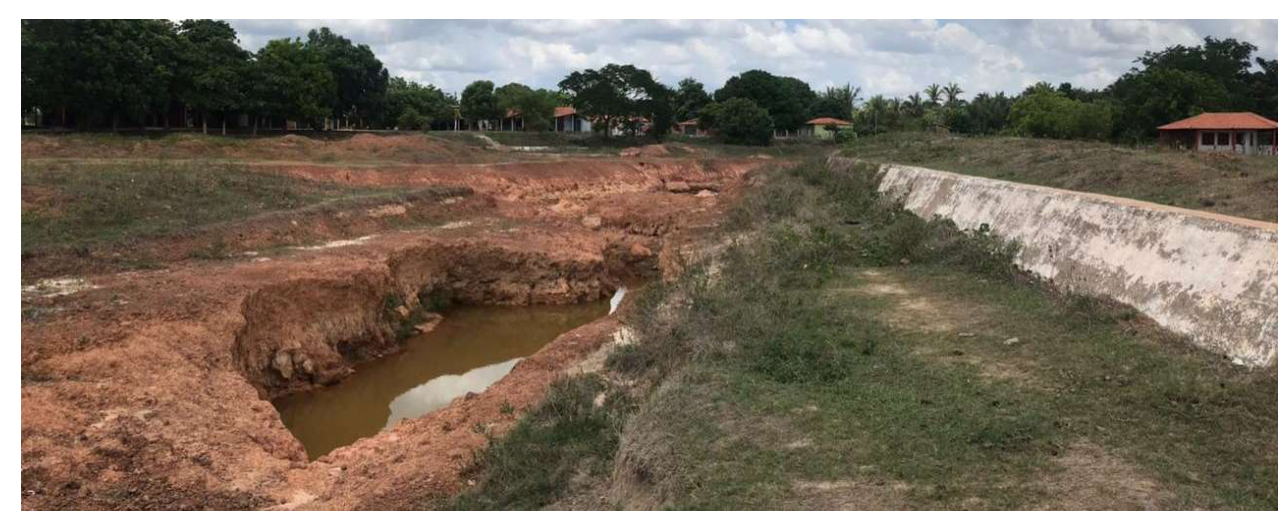

Figura 18: Fenômeno de erodibilidade do tipo voçoroca no sangradouro da barragem (Fonte: Autor, 2019)

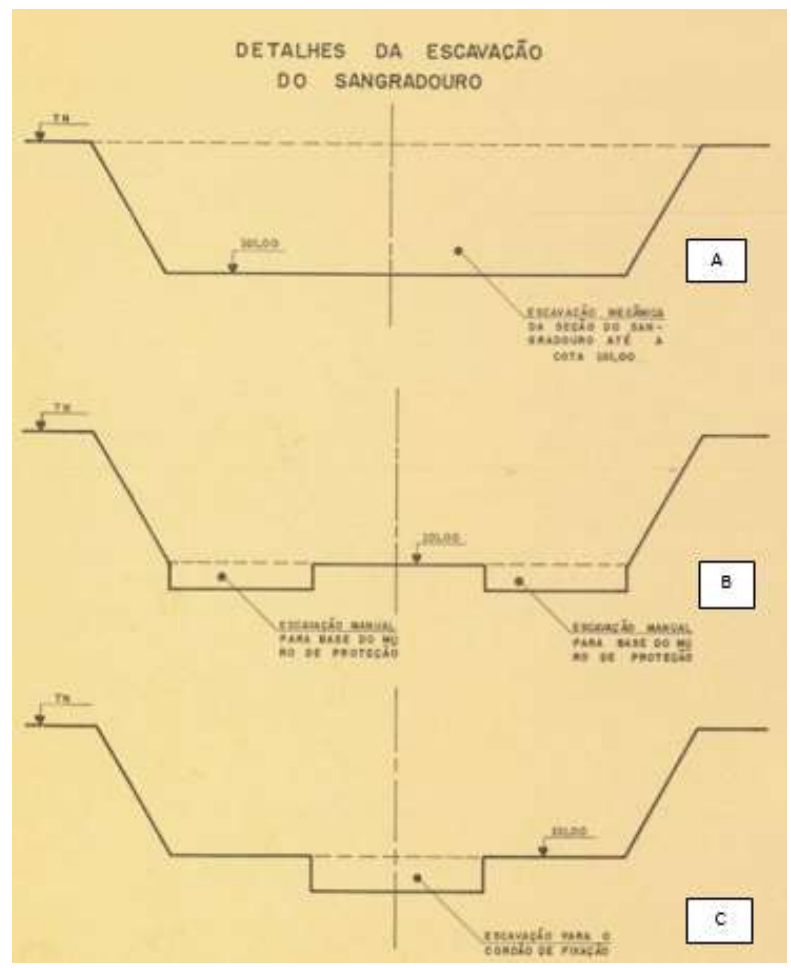

Figura 19: Escavação mecânica e manual sangradouro da Barragem do Bezerro (Fonte: IDEPI, 1992)

Esse fenômeno é potencializado pela tipologia do solo da barragem. Para identificar essas características, foram utilizados técnicas de geoprocessamento e constatou-se que são solos mais jovens (Plintossolos + Podzólico vermelhoamarelo + Neossolos Litólicos Eutróficos - Figura 20), com capacidade de permeabilidade e de estrutura porosa, e com vegetação desenvolvida (arbóreas) sobre o maciço, estes fatores, combinados, contribuem ainda mais para a susceptibilidade erosiva do solo, que também podem comprometer as fundações por infiltrações, que já ocorre, como foi observado na Figura 14.

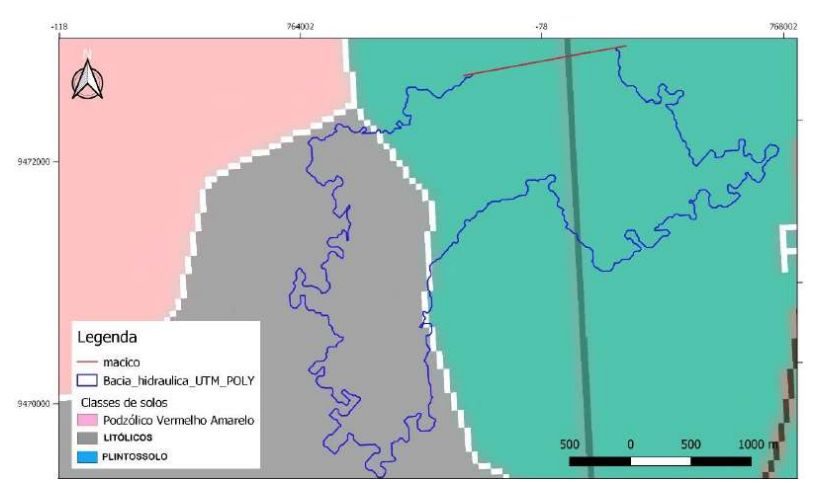

Figura 20: Mapa de solos da bacia hidráulica da Barragem do Bezerro (Fonte: EMBRAPA/SUDENE, 2006) 
Por fim, com o auxílio do software Google Earth, foi elaborado um croqui de localização dos principais pontos de problemas identificados na barragem (Figura 21). Indicado pelo número um (1) está o mecanismo de Tomada D’água ou acionamento (Figuras 4 a 7 da pesquisa); pelo número dois (2), está representada a região de infiltração e recalque da crista da barragem (Figuras 11 a 13 da pesquisa); e o número três (3) indica a região do sangradouro (Figura 17 da pesquisa), para este ainda foi executado uma ampliação da imagem de satélite representada na Figura 22.

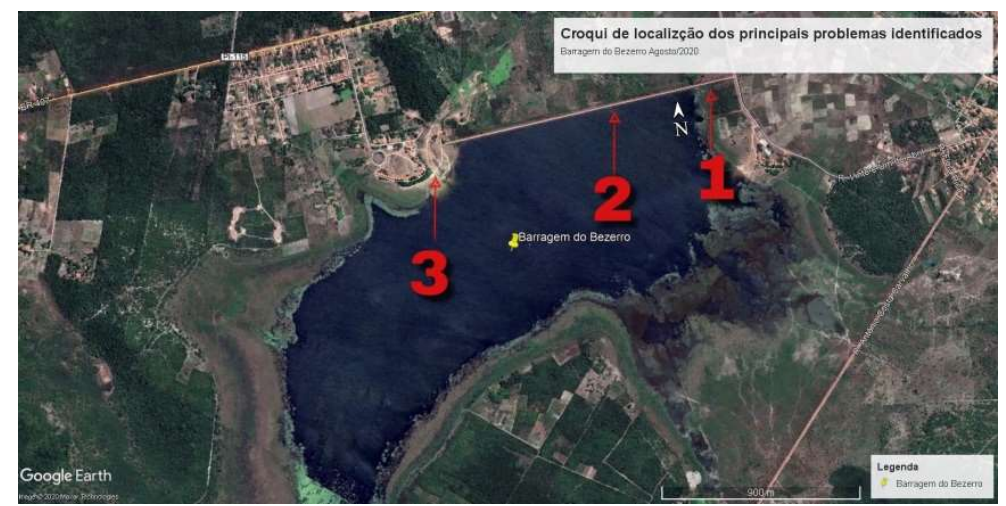

Figura 21: Localização dos principais problemas identificados na Barragem do Bezerro (Fonte: Autor, 2020)

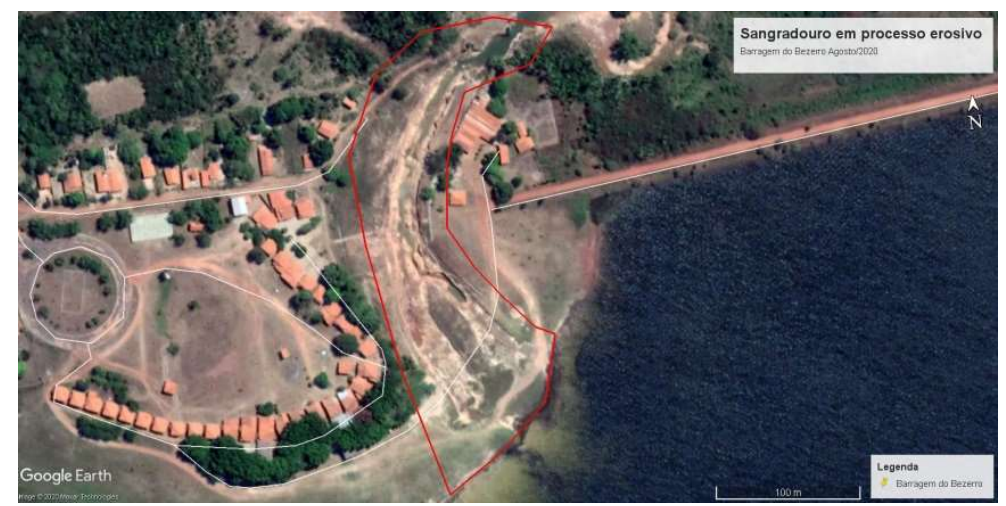

Figura 22: Sangradouro em processo erosivo (Fonte: Autor, 2020)

\section{CONCLUSÃO}

A partir da análise e discussão dos resultados obtidos conclui-se que:

- Não foi identificada a presença dos dispositivos necessários para garantir a segurança da população que vive no entorno da construção, como: comportas, dispositivo de acionamento de comportas, vários equipamentos de intrumentação (como: piezômetro, pêndulo, clinômetro, tensômetro, dentro outros), e iluminação normal e de emergência;

- O local encontra-se com necessidade de reparos; os dispositivos lá implantados, acionadores, bombas, condutos e vertedouros, estão deteriorados e, quando não, ineficientes;

- A vegetação que se instalou nos taludes causa preocupação, principalmente no talude à jusante. Suas raízes ao penetrarem no solo podem atingir o corpo da barragem, aumentando a possibilidade de percolação de água e diminuindo a resistência do mesmo;

- Não foram detectdos indícios do início da reforma definitiva prometida para o início de 2019. O local da falha estrutural encontra-se com reparos simples e de baixa eficiência;

- Sobre o item anterior, essa falha gerou consequências: a infiltração encontrada próximo ao talude à montante e, também, acredita-se que o recalque da crista da barragem diz respeito à percolação de água no corpo do maciço;

É importante ressaltar a urgência da necessidade de uma intervenção, dos órgaos competentes, na adequação da Barragem do Bezerro aos padrões de segurança exigidos, visto que o impacto de uma ruptura possui consequências relacionadas à vida das pessoas que vivem no entorno do local, além da inerente destruição ambiental que causaria. 
Por fim, neste sentindo, é possível ainda abrir discusões sobre outras barragens no Piauí e no Brasil, que, em muitos casos, não oferecem garantias de contenção de enchentes, sobretudo quando não possuem o acompanhamento necessário da gestão e acabam sendo negligenciadas, impactando ainda mais o meio ambiente e à vida humana.

\section{REFERÊNCIAS}

AGÊNCIA NACIONAL DE ÁGUAS (ANA). Guia Prático de Pequenas Barragens. 120p. Il. - Manual do Empreendedor sobre Segurança de Barragens, 8. Brasília, 2016; IBSN 978-85-8210-041-7.

AGÊnCIA NACIONAL DAS AGUAS (ANA). Manual De Políticas E Práticas De Segurança De Barragens Para Entidades Fiscalizadoras. 2015.

ALVARENGA, ANA; SOUSA, PAULO; Estudo da susceptibilidade erosiva do solo da Barragem do Bezerro no município de José de Freitas utilizando o sistema de informação geográfica. Piauí, 2019; Centro Universitário UNINOVAFAPI.

BRADY, N. C. WEIL, R. R. Elementos da natureza e propriedades dos solos. 3 ed. Porto Alegre: Bookman, 2013. $686 \mathrm{p}$.

BRASIL. TRIBUNAL SUPERIOR DO TRABALHO. Coordenação de Gestão Documental. Apostila de processo de restauração e materiais utilizados. Brasília: TST, 2012. Acesso em: 30 de maio, 2019.

FARIA, A. L. L.; SILVA, J. X.; GOES, M. H. B. Análise ambiental por geoprocessamento em áreas com susceptibilidade à erosão do solo na Bacia Hidrográfica do Ribeirão do Espírito Santo, Juiz De Fora (MG). Caminhos de Geografia. v.4, n.9, p.50-65, 2003.

JOHNSON, D. L. et al. Meaning of environmental terms. Journal of environmental quality, n. 26, p. 581-589, 1997.

KANASHIRO, WINSTON. Módulo I - Curso de Segruança de Barragens: aspectos legais, técnicos e socioambientair. Disponível em: <https://capacitacao.ead.unesp.br/>. Acesso em: 11 de out. De 2019.

MARQUES, F. P.L. e GERALDO, A. Barragens e Reservatórios. Geologia de Engenharia. Editores: Antonio M. S. Oliveira e. A. Brito, ABGE/ Fapesp, Sergio N São Paulo, 1998.

MARTINELLI, M. Mapas, gráficos e redes: elabore você mesmo. São Paulo: Oficina de Textos, 2014.

MINISTÉRIO DA INTEGRAÇÃO NACIONAL. SECRETARIA DE INFRAESTRUTURA HÍDRICA. Manual de Segurança e Inspeção de Barragens. Brasília - DF, 2002. Proágua / Semiárido - UGPO. Departamento de Projetos e Obras Hídricas (DPOH).

ROVANI F. F. M.; CASSOL R.; WOLlmANN $\quad$ C. A.; SIMIONI J. $\quad$ P. D. Análise da vulnerabilidade natural à perda de solo de 160 Rovani FFM, Viera $M$ Floresta e Ambiente. 2015; 23(2): 151-160 Barão de Cotegipe, RS. Revista do Departamento de Geografia - USP 2015; 29(1): 264-282.

SANTOS, C. A.; SOBREIRA, F. G. Análise morfométrica como subsídio ao zoneamento territorial: o caso das bacias do Córrego Carioca, Córrego do Bação e Ribeirão Carioca na região do Alto Rio das Velhas - MG. Revista Escola de Minas, v.61, p.77-85, 2008. SANTOS, R.F. Planejamento ambiental: teoria e prática. São Paulo: Oficina de Textos, 2004.

STEPHENS, Tim. Manual sobre pequenas barragens de terra. 2011. Disponível em: < http://www.fao.org/3/aba0081o.pdf $>$. Acessado em: 03 de junho de 2019.

TAYLOR, D.R. The Educational Challenges of New Cartography. Cartographical, No 4/1991, p. 19-37. 